\title{
Compulsive Masturbation Treated with Selective Serotonin Reuptake Inhibitors
}

\section{Naif Alsughier*}

Consultant Psychiatrist, Saudi Arabia

\section{Introduction}

Masturbation can be defined as a person's achieving sexual pleasure which usually results in orgasm by himself or herself (autoeroticism). Masturbation is a normal activity that is common in all stages of life from infancy to old age, but this viewpoint was not always accepted. Freud believed that neurasthenia was caused by excessive masturbation. In the early 1900s, masturbatory insanity was a common diagnosis in hospitals for the criminally insane in the United States. Masturbation is abnormal when it is the only type of sexual activity performed in adulthood, when its frequency indicates a compulsion or sexual dysfunction, or when it is consistently preferred to sex with a partner [1]. Compulsive masturbation does not have a distinct code in the Diagnostic and Statistical Manual of Mental Disorders, Fifth Edition D.S.M.-V (2013) but can be classified as other specified sexual dysfunction [2]. The I.C.D.-10 classifications (W.H.O., 1992) have a diagnostic category termed "excessive sexual desire" and compulsive masturbation may fall into this category [3]. Compulsive sexual behavior has been characterized as a behavioral addiction and an obsessive-compulsive spectrum disorder. It has been quantified using the statistic of total sexual outlet (number of orgasms/week). People with compulsive sexual behavior referred for treatment generally show a total sexual outlet of $>7$ [4]. Early psychological injury, from sexual abuse, physical abuse, exposure to violence, attachment trauma, or early sexualization, is at the root of sexually compulsive behavior $[4,5]$. Compulsive sexual behavior frequently has associated comorbidities of current mood disorders $33 \%$, anxiety disorders $42 \%$, substance disorders $29 \%$ and Personality disorders 46\% [6,7]. Physical injury in compulsive masturbation is common. Patients with this disorder may masturbate 5-15 times a day and loneliness is felt keenly after an orgasm. This disorder can interfere in occupational, social, interpersonal, and intimacy functioning. Many different agents have been cited in case reports as helpful in treating compulsive sexual behavior: lithium, buspirone, tricyclic antidepressants, selective serotonin reuptake inhibitors (SSRIs), atypical antipsychotics, naltrexone, and topiramate have all been reported to be helpful in treatment of sexual compulsivity [4].

\section{Case Description}

Mr. S, a 23 years old male student referred from urology clinic as the patient has penile erythema and skin abrasions due to excessive masturbation. He has a long history of excessive uncontrollable frequency of masturbation since 10 years comorbid with symptoms suggestive of generalized anxiety disorder. He is living with his family and his parents were overprotective since his early age. He had started masturbating at the age of 13 years associated with guilt feeling after each time he masturbates and he wanted to quit this habit. Repeated masturbation had affected his academic performance and he used to remain preoccupied with sexual thoughts most of the day. $\mathrm{He}$ attributed all his symptoms to his masturbation. He was observed by his family that he stays most of the day at his own room alone to watch pornographic movies. Initially at the age of 13 , his frequency of masturbation was once daily. The frequency of masturbation gradually increased to 8-10 times per day and used to spend long hours in the bathroom. In the last year, when frequency of masturbation increased, his study affected and his marks dropped. Also he started to be socially withdrawn. The patient tried to stop this habit but without success. Despite he feels this act is pleasurable but after the ejaculation he becomes dysphoric and feels guilty. There were no other symptoms of compulsive or impulse nature and no history of symptoms suggestive of mood episodes. He was never treated in the past. There was no history of major medical or surgical illness and no positive family history of any mental illness. During the interview he was anxious, agitated and distressed. He had low self esteem, excessive worry, preoccupied by this habit and its consequences. All routine investigations were carried out that yielded normal results. The patient's physical complaints (penile erythema and skin abrasions) were treated by urologist with topical medication. The patient was diagnosed as having other specified sexual dysfunction "compulsive masturbation" as per the D.S.M.- V Classification (A.P.A., 2013). He was started on Fluoxetine $20 \mathrm{mg} /$ day that was increased to $40 \mathrm{mg} /$ day after one week. Clonazepam $0.5 \mathrm{mg}$ /day was added (tapered off over next 2 weeks). At the end of 3 rd week, he showed an improvement and his masturbatory frequency decreased to 5-6 times per day. He asked to discontinue fluoxetine because of its side effects (restlessness and insomnia). He was shifted to paroxetine 12.5 $\mathrm{mg} /$ day for one week then increased gradually to $37.5 \mathrm{mg} /$ day within one month duration and psychology referral was made for behavioral therapy and supportive psychotherapy to build his self-esteem. At the end of 10th week of starting paroxetine his masturbatory frequency decreased to 1-3 times per week and his anxiety symptoms improved as well (Table 1). His academic performance returned to his baseline.

\section{Discussion}

According to D.S.M.-V compulsive masturbation can be classified as other specified sexual dysfunction [2], but in some references it is considered as an impulse control disorder [4] and other researchers consider it as variant of obsessive compulsive disorder [8] in which there is a phenomenological overlap of features of compulsive masturbation among these disorders [9]. There is scarcity of literature on the subject even in extensive reviews on compulsive sexual behaviors, and the disorder itself is rare $[10,11]$ and there are no epidemiologic studies of prevalence of compulsive masturbation [12]. Patients with compulsive

\begin{tabular}{|c|c|}
\hline Time & Masturbatory Frequency \\
\hline Before starting treatment & $8-10$ times/day \\
\hline After 3 weeks of starting fluoxetine & $5-6$ times/day \\
\hline After 2 weeks of starting paroxetine & $5-6$ times/day \\
\hline After 6 weeks of starting paroxetine & $1-3$ times $/$ day \\
\hline After 10 weeks of starting paroxetine & $1-3$ times/week \\
\hline
\end{tabular}

Table 1: Masturbatory frequency before and during treatment with paroxetine.

${ }^{*}$ Corresponding author: Naif Alsughier, Consultant Psychiatrist, Saudi Arabia, Tel: 00966504955085; E-mail: dr--naif@hotmail.com

Received April 07, 2015; Accepted May 30, 2015; Published June 06, 2015

Citation: Alsughier N (2015) Compulsive Masturbation Treated with Selective Serotonin Reuptake Inhibitors. J Psychiatry 18: 299 doi: 10.4172/23785756.1000299

Copyright: (c) 2015 Alsughier N. This is an open-access article distributed under the terms of the Creative Commons Attribution License, which permits unrestricted use, distribution, and reproduction in any medium, provided the original author and source are credited 
masturbation often present for treatment because the activity begin to consume many hours a day, interfering with work or a relationship [9]. Before initiating treatment in any form, the patient's motivation for treatment must be established. Treating the pre-morbid condition is also a pre-requisite to help the patient in overcoming his sexual problem. No controlled, randomized clinical trial on the medical treatment of compulsive masturbation was found in the literature review though anecdotal case reports exist. SSRIs are used for treatment for sexual compulsions. Initially the SSRIs were tried because of the expectation that their sexual side effects would be helpful in these compulsion. However, research suggests that reduction in symptoms is independent of sexual side effects and is a result of their anti-obsessional effects or a decrease in thoughts and urges. This is important, because an ideal treatment would suppress deviant and out-of-control sexual drives and behaviors but leave normative sexual interest and behaviors intact. There is no evidence that the SSRIs differ in efficacy [13]. Many cases reported that were successfully treated with SSRIs like fluoxetine, sertraline [14] and escitalopram [15]. Other medications can be used: aripiprazole [16], mirtazapine [17] and lamotrigine/fluoxetine combination [18]. Behavior therapy in the form of cognitive behavior therapy, covert sensitization and systematic desensitization has been reported useful [19]. In this case, considering that the patient had a partial benefit from fluoxetine treatment but could not continue due to its side effects like akathesia, paroxetine, with less incidence of this side effect and a known effect of reducing impulsive behaviors, was preferred and also it is approved to treat generalized anxiety disorder as well. All of reports, patients of this disorder are males as in this case and most of them are adolescents or young adults as our patient. All reports had at least one comorbid psychiatric disorder except one [14], but in these reports no similar comorbidity of anxiety disorder as in our patient. Also this case differs from reported cases that it complicated to cause physical injury which is penile erythema and skin abrasions. No trials are available of paroxetine for this disorder which tried in this case and responded well. This case responded to a combination of paroxetine and the combined use of supportive psychotherapy and behavioral modification techniques. Thus in the treatment of compulsive masturbation we feel that it is necessary in order to obtain a recovery, that a variety of interventions be used in a proper manner looking at the patient holistically and aiming to change not only biology but also environmental factors as well as family dynamics. There is a need for more studies for this disorder to determine its prevalence and to be classified to suitable category in which there is a phenomenological overlap of features between sexual dysfunctions, impulse control disorders and obsessive compulsive spectrum disorders. Also there is a need for randomized, controlled clinical trials about the use of SSRIs in the treatment of compulsive masturbation.

\section{Conclusion}

I conclude that it is important to find any comorbid psychiatric conditions in which its treatment can help managing compulsive masturbation. Any case of compulsive masturbation should be asked and examined for physical complication due to repeated masturbation which can be serious as in this case.

\section{References}

1. Sadock BJ, Sadock VA (2007) Kaplan \& Sadock's Synopsis of Psychiatry: Behavioral Sciences/Clinical Psychiatry, 10th Ed. Lippincott Williams \& Wilkins $686-688,712-713$.
2. Diagnostic and Statistical Manual-V (2013) American Psychiatric Association.

3. International Classification of Diseases-10 (1992) World Health Organization.

4. Mick TM, Hollander E (2006) Impulsive Compulsive Sexual Behavior, review article. CNS Spectrums 11: 944-955

5. Gerbe J (2008) Sexually Compulsive Behavior: Hypersexuality. Psychiatric Clinics of North America 31: 657-669

6. Raymond NC, Coleman E, Miner MH (2003) Psychiatric comorbidity and compulsive/impulsive traits in compulsive sexual behavior. Comprehensive Psychiatry 44: 370-380.

7. Kuzma JM, Black DW (2008) Sexually Compulsive Behavior: Epidemiology, Prevalence, and Natural History of Compulsive Sexual Behavior. Psychiatric Clinics of North America 31: 603-611.

8. Abramowitz JS (2007) Obsessive-Compulsive Disorder Subtypes and Spectrum Conditions. Elsevier 271-286.

9. Hollander E (1993) Obsessive-compulsive-related Disorders. American Psychiatric press 139-144.

10. Bancroft J, Vukadinovic Z (2004) Sexual addiction, sexual compulsivity, sexual impulsivity or what-towards a theoretical model. J Sex Res 41: 225-234.

11. Black DW, Kehrberg LL,Flumerfelt DL, Schlosser SS (1997) Characteristics of 36 subjects that reported compulsive sexual behaviour. Am J Psychiatry 154: 243-249.

12. Fatemi H, Clayton PJ (2008) The Medical Basis of Psychiatry. Humana Press 278-280.

13. Hollander E, Stein D (2007) Clinical Manual of Impulse-Control Disorders American Psychiatric Publishing 99-102.

14. Codispoti VL (2008) Pharmacology of Sexually Compulsive Behavior Psychiatric Clinics of North America 31: 671-679.

15. Herguner S (2009) Excessive masturbation in children and adolescents with autistic disorder: efficacy of escitalopram in three cases. Anatolian Journal of Psychiatry 10: 101.

16. Kul M, Baykan H, Kandemir H (2014) A Case of Excessive Masturbation Treated with Aripiprazole. Bulletin of Clinical Psychopharmacology 24: 93-96.

17. Albertini G, Polito E, Sarà M, Gennaro G, Onorati P (2006) Compulsive Masturbation in Infantile Autism Treated by Mirtazapine. Pediatric Neurology 34: 417-418.

18. Schupa C (2007) Lamotrigine/fluoxetine combination in the treatment of compulsive sexual behavior. Progress in Neuro-Psychopharmacology and Biological Psychiatry 31: 1337-1338.

19. McCarthy BW (1994) Sexually compulsive men and inhibited sexual desire. J Sex Marital Ther 20: 200-209. 